\title{
Gender differences in ankylosing spondylitis patients: Relation to clinical characteristics, functional status and disease activity
}

\author{
Maysa M Haroon*, Safaa Sayed \\ \& Tamer A Gheita \\ Department of Rheumatology, Faculty of \\ Medicine, Cairo University, Cairo, Egypt
}

Objective: To assess gender differences in Ankylosing Spondylitis (AS) patients regarding the clinical presentation, disease activity and functional status. Methods and findings: Forty AS patients; 21 males and 19 females, regularly following at the Rheumatology outpatient's clinic, Saudi German Hospital, Riyadh, KSA were included. Functional status and the disease activity were evaluated using Bath Ankylosing Spondylitis Functional Index (BASFI) and the Bath AS Disease Activity Index (BASDAI) respectively. Mean age was $34.3 \pm 8.5$ years with a comparable sex ratio (M:F 1.11:1). Morning stiffness was markedly lower in females ( $72.4 \pm 52.4$ vs $112.9 \pm 44.4$ minutes) ( $p=0.01)$.Bilateral sacroiliitis was significantly more in males ( $n=18 ; 85.7 \%$ vs $n=13 ; 68.4 \%)(p=0.02)$.The Schöber's test was more limited and the finger-to-floor distance more increased in males $(4.5 \pm 0.8 \mathrm{~cm}$ and $40.7 \pm 9.2 \mathrm{~cm}$ vs $4.9 \pm 0.7$ $\mathrm{cm}$ and $27.9 \pm 9.7 \mathrm{~cm} ; \mathrm{p}=0.046$ and $\mathrm{p}<0.001$ respectively). Human leukocytic antigen-B27) was positive in $85.7 \%$ of males while rheumatoid factor was positive in only 3 females. BASFI showed significantly higher value in females $(6.7 \pm 1.1$ vs $5.8 \pm 1.4)$ ( $p=0.04)$, while BASDAl showed only a tendency to be higher in females. Using Magnetic resonance imaging of the sacroiliac joint, sacroiliitis was detected in all cases with signs of activity in 9 males and 7 females, erosions in 8 males and 5 females, effusion in 1 female and total ankylosis in 1 male. Conclusion: The clinical presentation and genetic background were more remarkable in the AS males; however the disease activity and functional impairment were increased in females. Radiological findings were comparable.Understanding the gender differences in AS may discern how this may impact future research, diagnosis and treatment.

Keywords: ankylosing spondylitis - gender • BATH Ankylosing Spondylitis Functional Index (BASFI) • Bath Ankylosing Spondylitis Disease Activity Index (BASDAI)

\section{Introduction}

Ankylosing Spondylitis (AS) is one of the chronic rheumatic diseases, characterized by inflammation primarily affecting the spine (vertebrae and intervertebral discs) and the sacroiliac joints. In severe cases, inflammation may become accompanied with new bone formation (syndesmophytes) leading to impaired back mobility [1]. Estimates of prevalence of (AS) have varied widely depending on the population studied [2]. There are conflicting opinions with respect to the occurrence of AS in females, being considered extremely rare in women [3] whereas a less pronounced male dominance of the disease has recently been indicated [4].

Presence of gender-attributable differences in AS patients regarding disease characteristics, radiographic damage, clinical outcome and response to treatment has been suggested [5]. In case of females, the disease tends to be milder leading to longer delay-in, or even under diagnosis. Male AS patients are more likely to develop radiographic spinal damage [6]. Recently, it has become increasingly evident that the risk factors for spinal radiographic progression are partly different between males and females. Whilst obesity and baseline AS-associated spinal radiographic changes predicted progression in both sexes similarly, yet a high C-reactive protein (CRP) and smoking were among progression risk factors in males, and bisphosphonates usage was a risk factor in females [7].

Generally, women suffer from pain more than men due to a probably lower pain threshold. Therefore, women are less tolerant to pain which 
seems to be insufficiently treated [8]. While in AS, it was observed that women had 3 times more common axial thoracic pain. Cervicothoracic junction pain was also more widely distributed, and widespread axial and peripheral articular pains were more likely increased among females [9]. As regards clinical manifestations, peripheral arthritis has been reported more often among females [10]. Inflammatory bowel disease, however, does not show any higher tendency towards either sex. In other words, it seems not gender-related [11]. Nevertheless, genderattributable difference in the prevalence of acute anterior uveitis is a matter of debate with conflicting results [12]. Regarding the patientreported outcomes, scores of (nocturnal) back pain, disease activity and functional outcome are frequently worse among female patients [13]. Gender may also have its impact on management as treatment with biologics was associated with a yearly reduction in the estimated glomerular filtration rate that was more evident among AS males [14].

Better understanding of theses gender-related differences is highly important. The increased awareness of such differences could help in improvement of health care provision, as well as, disease outcome for female AS patients specifically, who have been under-reported in the past.

The purpose of this work was to assess gender differences between male and female AS patients regarding the clinical characteristics, functional ability and disease activity.

\section{Patients and methods}

Nineteen AS female patients and 21 males (diagnosed according to the modified New York criteria [15] were included in the present cross-sectional study. Patients were regular following-up-patients at the Rheumatology outpatients clinic of the Saudi German Hospital, Riyadh, KSA. The study conforms to the ethical standards of the 1964 Helsinki Declaration. It was, also, approved by the local ethics committee. Moreover, Patients gave informed consent to be included in the study.

For all the patients, demographic data (including: age, sex, disease duration, age at disease onset) and clinical data (including: peripheral arthritis, axial joints involved and uveitis) were reported. Using the Bath AS Functional Index (BASFI) [16] and the Bath AS Disease Activity Index (BASDAI) [17], functional ability and disease activity were measured respectively. The modified Schöber's test was used to assess the spine mobility [18]. Grading of the sacroiliitis as well as assessment of syndesmophytes were done using sacroiliac and lumbosacral magnetic resonance imaging (MRI). Sacroiliitis was defined, according to the New York criteria, by signal characteristic of the joint space, presence of bone marrow oedema or erosion adjacent to the joint [19]. Determinants of active inflammation include the presence of high signal intensity on T2 image (erosions), subchondral oedema and enhancement within or adjacent to the sacroiliac joint. Whereas chronic sacroiliitis was marked by presence of joint space narrowing, bone bridging, low signal intensity on T1 and T2 weighted images and subchondral sclerosis. Active inflammatory markers were also determined including erythrocyte sedimentation rate (ESR) and CRP (by ELISA, normal values $<5 \mathrm{mg} / \mathrm{L})$.

\section{Results}

The study was conducted on 40 AS patients 21 males and 19 females (M:F 1.11:1) with a mean age of $34.3 \pm 8.5$ years, age at onset of $28.9 \pm$ 6.8 years and IBP duration of $4.9 \pm 7.5$ years. The comparison of the demographic features, clinical and laboratory characteristics, disease activity and functional status of the patients according to the gender are presented in Table 1. Both genders were similarly using Non-Steroidal Anti-Inflammatory Drugs (NSAIDs), disease modifying drugs (DMARDs) and tumour necrosis factor-a (TNF $\alpha$ ) blockers (infliximab, etanercept and adalimumab). MRI of the sacroiliac joint (SIJ) revealed sacroiliitis in all the cases with signs of activity in 9 males and 7 females, erosions in 8 males and 5 females, effusion in 1 female and total ankylosis in 1 male.

\section{Discussion}

Initially, ankylosing spondylitis was considered one of the chronic inflammatory diseases that primarily affected men. In 1949 , the male to female ratio was estimated to be 10:1. However, a newer prevalence 2-3:1 has been suggested [6]. Hill et al. concluded that, "The precise ratio is less important than the fact that AS does occur in women and should be included in the differential diagnosis of back pain" [20].

In the current study, the male: females ratio was $1.11: 1$ with a mean age of $34.3 \pm 8.5$ years, age at onset of $28.9 \pm 6.8$ years in females and 29.4 \pm 6.9 in males and this is in agreement with Lee et al. who found that women had a slightly 


\begin{tabular}{|c|c|c|c|}
\hline \multirow[t]{2}{*}{ Parameter } & \multicolumn{2}{|c|}{$\begin{array}{l}\text { AS patients }(n=40) \\
\text { Mean } \pm \text { SD or } n(\%)\end{array}$} & \multirow[t]{2}{*}{$P$ value } \\
\hline & Male $(n=21)$ & Female $(n=19)$ & \\
\hline Age (years) & $35.4 \pm 9.3$ & $33.1 \pm 7.4$ & 0.39 \\
\hline Age at onset (years) & $29.4 \pm 6.9$ & $28.5 \pm 6.8$ & 0.7 \\
\hline Back MS (minutes) & $112.9 \pm 44.4$ & $72.4 \pm 52.4$ & 0.01 \\
\hline IBP duration (years) & $5.6 \pm 7.8$ & $4.2 \pm 7.2$ & 0.56 \\
\hline Bilateral sacroiliitis & $18(85.7)$ & $13(68.4)$ & 0.02 \\
\hline Peripheral arthritis & $9(42.9)$ & $4(21.1)$ & 0.15 \\
\hline Uveitis & $1(4.8)$ & $0(0)$ & 0.33 \\
\hline Schöber's test (cm) & $4.5 \pm 0.8$ & $4.9 \pm 0.7$ & 0.046 \\
\hline Finger-to-floor (cm) & $40.7 \pm 9.2$ & $27.9 \pm 9.7$ & $<0.001$ \\
\hline Chin-to-chest (mm & $0.06 \pm 0.14$ & $0.02 \pm 0.07$ & 0.24 \\
\hline Occiput-to-wall (mm) & $0.22 \pm 0.34$ & $0.03 \pm 0.11$ & 0.02 \\
\hline Chest expansion $(\mathrm{cm})$ & $4.2 \pm 1.1$ & $4.8 \pm 0.51$ & 0.06 \\
\hline $\mathrm{ESR}\left(\mathrm{mm} / 1^{\mathrm{st}} \mathrm{hr}\right)$ & $42.3 \pm 30.8$ & $25.2 \pm 25.9$ & 0.06 \\
\hline CRP $(\mathrm{mg} / \mathrm{dl})$ & $41.04 \pm 39.6$ & $10.1 \pm 14.7$ & 0.003 \\
\hline RF positivity & $0(0)$ & $3(15.8)$ & - \\
\hline HLA-B27 positivity & $18(85.7)$ & $9(47.4)$ & - \\
\hline BASDAI & $5.7 \pm 1.9$ & $6.5 \pm 1.4$ & 0.16 \\
\hline BASFI & $5.8 \pm 1.4$ & $6.7 \pm 1.1$ & 0.04 \\
\hline \multicolumn{4}{|c|}{$\begin{array}{l}\text { MS: morning stiffness, IBP: inflammatory back pain, ESR: erythrocyte sedimentation rate, CRP: C-reactive protein } \\
\text { RF: rheumatoid factor, HLA-B27: human leucocyte antigen, BASDAI: Bath ankylosing spondylitis disease activity } \\
\text { index, BASFI: Bath ankylosing spondylitis functional index. Bold values are significant at } p<0.05 \text {. }\end{array}$} \\
\hline
\end{tabular}

earlier age of disease onset than men [21]. In this work, the HLA-B27 was positive in $67.5 \%$ of the patients. In a recent study from Upper Egypt on AS, the ratio was 2.9:1. HLA-B27 was positive in $74.5 \%$ of the patients, $25.7 \%$ had a family history of AS, peripheral arthritis was present in $20 \%$ and anterior uveitis in $7.1 \%$. The mean BASDAI and BASFI were $4.8 \pm 1.18$ and $5.4 \pm$ 1.5 , respectively. Axial radiographic damage was significantly greater in men [22].

Special hormonal, immunological and genetic sex-related factors may play a role in the variability of AS disease characteristics in females [23]. Furthermore, poor sleep was found to be strongly associated with female sex [24]. Women with AS, as well, tend to have more peripheral joint pain than men with AS [25]. However this was not the case in the present work as peripheral arthritis tended to be increased in males. Though, in another recent study, there were no genderattributable differences between AS patients as regards peripheral and axial joint involvement [26].

The BASDAI and BASFI in the current study showed higher values in females. The Brazilian Registry of Spondyloarthritis reported similar data in 1505 patients [27]. Moreover, in accordance, disease activity (BASDAI) and functionality (BASFI) were significantly higher in female patients at any given level of radiographic damage and self-reported functional limitations were worse for women [21]. Rusman et al. likewise, reported that the load of the disease in females was higher, probably because of delayed diagnosis, more active disease and less response to treatment with biologics, although men had poor prognosis regarding radiological progression [23]. On the other hand, Swinnen et al. observed that BASFI and BASDAI were worse in men, although they documented increased likelihood of widespread axial and peripheral articular pain among women [9]. In another study, there was no difference in disease activity or physical function over time between both sexes. Interestingly, in their cohort, men had a better quality of life over time in spite of more advanced radiographic changes [28].

As a chronic inflammatory disease affecting the musculoskeletal system, AS can result in serious functional complications and disabilities which represent a health care challenge. The effective management for such a chronic disease model entails that there be cooperation between patients and health care provider within an integrated system which includes self-management, education and follow-up for getting the utmost care [29]. The essential part of effective management for chronic conditions 
is the partnership between the patient and health care provider because it provides the opportunity to empower patients to become more active in managing their health. When patients are incorporated in this process through more education and more involvement they become enabled to take actions that will promote healthier outcomes [30]. This applies to AS disease and is especially important for physicians working directly with individual patients, helping them to make lifestyle changes, monitoring their conditions, and providing the necessary information and advice to promote patient empowerment, enhance self-management skills, and achieve better compliance with care recommendations and follow-up of the disease. This can result in a true improvement in the clinical manifestations of the patients treated [31].

As the case with all researches, our study is not without limitations. The most important limitation is the small number of patients which makes precise generalized conclusions potentially arguable. Nonetheless, AS may be even rarer in the Middle Eastern and Arab countries [32]. A longitudinal study with further indepth analysis is recommended to verify the reached findings, to determine the response to medications, detect the disease outcome and any confounding factors.

In conclusion, the clinical presentation and genetic background were more remarkable in the AS males; however the disease activity and functional impairment were increased in females. Radiological findings were comparable. Understanding the gender differences in AS may discern how this may impact future research, diagnosis and treatment.

Conflicts of interest

None

Funding

Not applicable (no funding body)

\section{References}

1. Gilgil E, Kaçar C, Tuncer T, et al. The association of syndesmophytes with vertebral bone mineral density in patients with ankylosing spondylitis. J. Rheumatol. 32, 292-294 (2005).

2. Carter ET, McKenna $\mathrm{CH}$, Brian DD, et al. Epidemiology of spondyloarthritis in Rochester, Minnesota, 1935-1973. Arthritis. Rheum. 22(4), 365370 (1979).

3. West HF. The aetiology of ankylosing spondylitis. Ann. Rheum. Dis. 8(2), 143-148 (1949).
4. Calin A, Fries JF. Striking prevalence of ankylosing spondylitis in 'healthy' W27 positive males and females. N. Engl. J. Med. 293(17), 835-839 (1975).

5. Feldtkeller E, Bruckel J, Khan MA. Scientific contributions of ankylosing spondylitis patient advocacy groups. Curr. Opin. Rheumatol. 12(4), 239247 (2000).

6. Lee W, Reveille JD, Weisman MH. Women with ankylosing spondylitis: a review. Arthritis. Rheum. 59(3), 449-454 (2008).

7. Deminger A, Klingberg E, Geijer M, et al. A five-year prospective study of spinal radiographic progression and its predictors in men and women with ankylosing spondylitis. Arthritis. Res. Ther. 20(1), 162 (2018).

8. Pinn VW. Sex and gender factors in medical studies: implications for health and clinical practice. JAMA. 289(4), 397-400 (2003).

9. Swinnen TW, Westhovens R, Dankaerts W, et al. Widespread pain in axial spondyloarthritis: clinical importance and gender differences. Arthritis. Res. Ther. 20(1), 156 (2018)

10. Ibn Yacoub Y, Amine B, Laatiris A, et al. Gender and disease features in Moroccan patients with ankylosing spondylitis. Clin. Rheumatol. 31(2), 293-297 (2012).

11. Kennedy LG, Will R, Calin A. Sex ratio in the spondyloarthropathies and its relationship to phenotypic expression, mode of inheritance and age at onset. J. Rheumatol. 20, 1900-1904 (1993).

12. Slobodin G, Reyhan I, Avshovich N, et al. Recently diagnosed axial spondyloarthritis: gender differences and factors related to delay in diagnosis. Clin. Rheumatol. 30(8), 1075-1080 (2011).

13. Roussou E, Sultana S. Spondyloarthritis in women: differences in disease onset, clinical presentation, and Bath Ankylosing Spondylitis Disease Activity and Functional Indices (BASDAI and BASFI) between men and women with spondyloarthritides. Clin. Rheumatol. 30(1), 121-127 (2011).

14. Kim SK, Choe JY. Gender is a risk factor for annual decline in estimated glomerular filtration rate in patients treated with biological DMARDs in rheumatoid arthritis and ankylosing spondylitis: a retrospective observational study. J. Korean. Med. Sci. 33(30), e188 (2018).

15. Van Der Linden S, Valkenburg HA, Cats A. Evaluation of diagnostic criteria for ankylosing spondylitis. A proposal for modification of the New York criteria. Arthritis. Rheum. 27(4), 361-368 (1984).

16. Rostom S, Benbouaaza K, Amine B, et al. Psychometric evaluation of the Moroccan version of the Bath Ankylosing Spondylitis Functional Index (BASFI) and Bath Ankylosing Spondylitis Disease Activity Index (BASDAI) for use in patients with ankylosing spondylitis. Clin. Rheumatol. 29(7), 781-788 (2010).

17. Garrett $S$, Jenkinson T, Kennedy LG, et al. A new approach to defining disease status in ankylosing spondylitis: the Bath Ankylosing Spondylitis Disease Activity Index. J. Rheumatol. 21, 2286-2291 (1994).

18. Lee YS, Schlotzhauer T, Ott SM, et al. Skeletal status of men with early and late ankylosing spondylitis. Am. J. Med. 103(3), 203-241 (1997). 

functional status and disease activity

19. Mackay K, Mack C, Brophy S, et al. The Bath Ankylosing Spondylitis Radiology Index (BASRI). Arthritis. Rheum. 41(12), 2263-2270 (1998).

20. Hill HF, Hill AG, Bodmer JG. Clinical diagnosis of ankylosing spondylitis in women and relation to presence of HLA-B27. Ann. Rheum. Dis. 35(3), $267-$ 270 (1976).

21. Lee W, Reveille JD, Davis JC Jr, et al. Are there gender differences in severity of ankylosing spondylitis? Results from the PSOAS cohort. Ann. Rheum. Dis. 66(5), 633-638 (2007).

22. MoshrifA, Mosallam A, Rayan M, et al. Characterization of ankylosing spondylitis in Upper Egypt. Int. J. Clin. Rheumatol. 13(1), 52-59 (2018).

23. Rusman T, van Vollenhoven RF, van der Horst-Bruinsma IE. Gender differences in axial spondyloarthritis: women are not so lucky. Curr. Rheumatol. Rep. 20(6), 35 (2018).

24. Wadeley A, Clarke E, Leverment S, et al. Sleep in ankylosing spondylitis and non-radiographic axial spondyloarthritis: associations with disease activity, gender and mood. Clin. Rheumatol. 37(4), 1045-1052 (2018).

25. Will R, Edmunds L, Elswood J, et al. Is there sexual inequality in ankylosing spondylitis? A study of 498 women and 1202 men. J. Rheumatol. 17, 1649-1652 (1990).

26. Bouraoui A, Roussou E, Sakthibalan S, et al. Spondyloarthropathies: are there any differences between Caucasians and southeast Asians living in north-east London in terms of disease onset and progression subject to cultural, social and treatment applications. Int. J. Clin. Rheumatol. 13(2), 121-124 (2018).

27. De Carvalho HM, Bortoluzzo AB, Gonçalves CR da Silva JA, et al. Gender characterization in a large series of Brazilian patients with spondyloarthritis. Clin. Rheumatol. 31(4), 687-695 (2012).

28. Webers C, Essers I, Ramiro S, et al. Gender-attributable differences in outcome of ankylosing spondylitis: long-term results from the Outcome in Ankylosing Spondylitis International Study. Rheumatology (Oxford). 55(3), 419-428 (2016).

29. Bodenheimer T, Lorig K, Hlasted H, et al. Patient selfmanagement of chronic disease in primary care. JAMA 288(19), 2469-2475 (2002).

30. Wagner EH. Chronic disease management: what will it take to improve care for chronic illness? Eff. Clin. Pract. 1(1), 2-4 (1998).

31. Ciccone MM, Aquilino A, Cortese F, et al. Feasibility and effectiveness of a disease and care management model in the primary health care system for patients with heart failure and diabetes (Project Leonardo). Vasc. Health. Risk. Manag. 6, 297-305 (2010).

32. Ziade NR. HLA B27 antigen in Middle Eastern and Arab countries: systematic review of the strength of association with axial spondyloarthritis and methodological gaps. BMC. Musculoskelet. Disord. 18(1), 280 (2017). 